COVID-19: information on accessing the platform off-site here.

Welcome Guest user

Enter your search terms here

Q Advanced search

Home / Journals / Corporate Communications: An International Journal

/ Multidisciplinarity in internal communication and the challenges ahead

\title{
Multidisciplinarity in internal communication and the challenges ahead
}

Milena Araújo, Sandra Miranda

Corporate Communications: An International

Journal

ISSN: $1356-3289$

Antoffchatidipnalte: 5 October 2020

Stangdard $d_{\text {ermissions }}$

Serial

Number.) 
COVID-19: information on accessing the platform off-site here.

Welcome Guest user

Q Advanced search

Home / Journals / Corporate Communications: An International Journal

/ Multidisciplinarity in internal communication and the challenges ahead

main trends influencing both the academic and professional fields.

\section{Design/methodology/approach}

Departing from a communicational background, the authors integrate dispersed contributions from disciplines such as organizational communication, public relations, corporate communication and marketing communications, to the literature on internal communication.

\section{Findings}

The significant role played by internal communication is supported by scholars with different theoretical backgrounds. Despite the clear differences between disciplines, the defense of a stratcgized internal communication and a focus on the employee is widely accepted.

\section{Practical implications}

Buth scholars and practilioners will need to keep adapling lo a reality where: internal communication practices are not only managerial but also dependent on the inputs of the employees; the ability to listen and collect feedback is sacred, and interna communication plans are expected to be strategically implemented and measured.

\section{Originality/value}

By showing the plurality of disciplines that influence internal communication, a strategized multidisciplinary focus on the topic is encouraged.

\section{Keywords}

\author{
Internal communication Employee communication \\ Strategic communication Strategy Multidisciplinarity

\section{Citation} \\ Aralíjo, M. and Miranda, S. (20)0), "Multidisciplinarity in internal \\ communication and the challenges ahead", Corporate
}

$\angle U \angle U$

Promoting perceived insider status of indigenous employees Joanie Caron et al., Cross Cultural \& Strategic Management, 2019

Reviewing corporate social responsibility communication: a legitimacy perspective Anne Ellerup Nielsen et al. Corporate Communications: An International Journal, 2018

Sustainability strategy and blockchain-enabled life cycle assessment: a focus on materials industry

David Teh et al., Environment Systems and Decisions, 2020

Vying for seats in the C-suite: Marketing and PR's focus is too narrow, study finds

Phys.org, 2015

BioNTech's Personalized Cancer Vaccine With Tecentriq Shows Encouraging Activity in Solid Tumors

Precision Oncology News, 2020

Powered by TREND MD

I consent to the use of Google Analytics and related cookies across the TrendMD network (widget, website, blog). Learn more Yes No 
COVID-19: information on accessing the platform off-site here.

Welcome Guest user

Q Advanced search

Home / Journals / Corporate Communications: An International Journal

/ Multidisciplinarity in internal communication and the challenges ahead

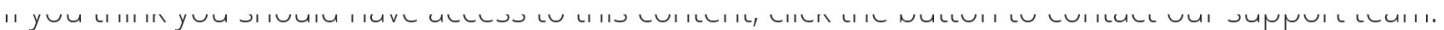

\section{Contact us} $D$

Services

Authors

Editors

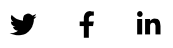

(c) 2020 Emerald Publishing Limited
Librarians

Researchers

Reviewers
About

About Emerald

Working for Emerald

Contact us

Publication Sitemap
Policies and information

Privacy notice

Site policies

Modern Slavery Act

Chair of Trustees governance

statement

COVID-19 policy 